\title{
Inhibition of Jun N-Terminal Kinase (JNK) Enhances Glucocorticoid Receptor-Mediated Function in Mouse Hippocampal HT22 Cells
}

\author{
Xiaohong Wang ${ }^{1, *}$, Huixia Wu', Viraj S Lakdawala', Fang Hu', Nicola D Hanson' and Andrew H Miller,', \\ 'Department of Psychiatry and Behavioral Sciences, Emory University School of Medicine, Atlanta, GA, USA
}

\begin{abstract}
Mitogen-activated protein kinases (MAPKs), including Jun N-terminal kinase (JNK), promote inflammatory and proliferative responses to infection and other environmental stimuli including stress. Relevant to negative regulation of inflammatory pathways by glucocorticoids and the development of glucocorticoid resistance (observed in inflammatory disorders as well as certain neuropsychiatric disorders such as major depression), activation of JNK has been reported to inhibit glucocorticoid receptor (GR) function. In this study, the role of JNK pathways in modulating GR function was further investigated. Treatment of mouse hippocampal (HT22) cells with the selective JNK inhibitor, SP-600I25 (0.1-10 $\mu \mathrm{M})$, resulted in dose-dependent induction of GR-mediated MMTV-luciferase activity. SP-600I25 also significantly enhanced dexamethasone-induced MMTV-luciferase activity, while increasing GR binding to the glucocorticoid responsive element, both in the presence and absence of Dex. Similar effects were observed in mouse fibroblast cells (LMCAT), and in HT22 cells treated with a JNK specific antisense oligonucleotide. The induction of GR-mediated function by SP-600I25 was not due to altered cytosolic GR binding or GR protein expression or enhancement of GR nuclear translocation as determined by Western blot. Taken together, the data indicate that constitutive expression of JNK plays a tonic inhibitory role in GR function, which is consistent with findings that activation of JNK pathways inhibits GR. The data also identify potential pathways involved in the pathogenesis of the glucocorticoid resistance found in certain chronic immune/inflammatory diseases and subgroups of patients with major depression. Moreover, JNK pathways may represent a therapeutic target for normalization of GR function in these disorders.

Neuropsychopharmacology (2005) 30, 242-249, advance online publication, 10 November 2004; doi: I 0. I038/sj.npp. I 300606
\end{abstract}

Keywords: JNK; glucocorticoid receptor; MAP kinase; cytokine; depression; inflammation

\section{INTRODUCTION}

Glucocorticoid inhibition of inflammation plays an essential role in the regulation of the immune response in both health and disease. Indeed, diseases characterized by glucocorticoid resistance, including several autoimmune disorders, infectious diseases, and certain neuropsychiatric disorders such as major depression, are associated with increased inflammation, which in turn is believed to contribute to disease expression and progression (Holsboer, 2000; Pariante and Miller, 2001; Corrigan et al, 1991; Sher et al, 1994; Spahn et al, 1996; Norbiato et al, 1996; Raison and Miller, 2001; Lamberts, 1996; Shimada et al, 1997). Increasing data suggest that there is considerable crosstalk

\footnotetext{
*Correspondence: Professor AH Miller, Department of Psychiatry and Behavioral Sciences, Emory University School of Medicine, 1639 Pierce Dr, Suite 4000, Atlanta, GA 30322, USA, Tel: + I 404727 8260, Fax: + | 404727 3233, E-mail: amill02@emory.edu

"Deceased.

Received 27 January 2004; revised 26 August 2004; accepted 21 September 2004

Online publication: 10 June 2004 at http://www.acnp.org/citations/ NPPI00604040035/default/pdf
}

between the pathways that subserve glucocorticoid and inflammatory signaling. For example, a number of studies have demonstrated that activation of proinflammatory cytokine signaling pathways, including mitogen-activated protein kinases (MAPK), is associated with decreased functional activity of the glucocorticoid receptor (GR) (Miller et al, 1999; Pariante and Miller, 2001; Wang et al, 2004).

c-Jun N-terminal kinase (JNK) is a member of the MAPK family that is activated in response to inflammatory cytokines and environmental stress. Upon activation by extracellular signals, JNK phosphorylates its major target, cJun, an important component of AP-1, which modulates cell proliferation and inflammation (Manning et al, 2003; Weston and Davis, 2002). Several studies have indicated that there is relevant cross-talk between GR and AP-1 (Jonat et al, 1990; Schule et al, 1990; Yang-Yen et al, 1990). For example, GR and AP-1 exhibit mutual suppression in a transcription and translation independent manner (Reichardt et al, 1998). Indicating the relevant role of protein-protein interactions in these findings, GR has been found to co-precipitate with AP-1 when using antibodies to either Jun or GR (Jonat et al, 1990; Yang-Yen et al, 1990). 
More recently, JNK was found to phosphorylate GR directly and inhibit GR-mediated function (Rogatsky et al, 1998). Taken together, the data suggest that JNK signaling pathways may play a role in modulating GR function and provide evidence that activation of JNK may contribute to the glucocorticoid resistance found in certain chronic inflammatory and infectious diseases as well as major depression. Nevertheless, the role of constitutive JNK expression in the regulation of GR function has not been examined.

In this study, we investigated the impact of JNK activity on GR function under basal conditions in mouse hippocampal and fibroblast cell lines using a JNK selective inhibitor (SP-600125) or a JNK antisense oligonucleotide. The results demonstrate that inhibition of JNK activity is associated with significant enhancement of GR-mediated function, both in the presence and absence of dexamethasone (Dex).

\section{MATERIALS AND METHODS}

\section{Materials}

Chemicals. Sources of reagents were as follows: SP-600125 from BIOMOL Research Laboratories Inc. (Plymouth Meeting, PA), dexamethasone and corticosterone from SIGMAADRICH Co. (St Louis, MO), Lipofectin from Invitrogen Corporation (Carlsbad, CA), and BCA Protein Assay Reagent from PIERCE ENDOGEN (Rockford, IL).

Cell culture. Mouse hippocampal HT22 cells were kindly provided by Dr Y Sagara (University of California, San Diego, La Jolla, CA) and were grown at $37^{\circ} \mathrm{C}$ with $5 \% \mathrm{CO}_{2}$ in DMEM supplemented with $10 \%$ heat-inactivated $\left(56^{\circ} \mathrm{C}\right.$, $30 \mathrm{~min}$ ) fetal bovine serum (Hyclone, Logan, UT), $50 \mathrm{U} / \mathrm{ml}$ penicillin, and $50 \mu \mathrm{g} / \mathrm{ml}$ streptomycin.

Mouse fibroblast LMCAT cells stably transfected with a construct containing MMTV and CAT reporter gene were generously provided by Dr ER Sanchez (Medical College of Ohio, Toledo, OH). Cells were grown in $175-\mathrm{cm}^{2}$ flasks in DMEM medium (Invitrogen Corporation, Carlsbad, CA) with $10 \%$ stripped newborn calf serum (charcoal/dextranextracted, heat-inactivated) at $37^{\circ} \mathrm{C}$ with $5 \% \mathrm{CO}_{2}$ in ambient air. The stably transfected GRE-CAT reporter construct was maintained in the presence of $0.2 \mathrm{mg} / \mathrm{ml}$ G418 sulfate (geneticin) antibiotic. Appropriate vehicle controls were used in all experiments, and each experimental condition included at least three replicates.

CAT assay. CAT concentrations induced by Dex were measured using the commercial CAT ELISA kit from Roche Diagnostics (Indianapolis, IN). Before assay, the cells were washed three times with cold $1 \times$ PBS and then lysed with the provided buffer after incubation at room temperature (RT) for $30 \mathrm{~min}$. Cell extracts were then spun at $23000 \mathrm{~g}$ at $4^{\circ} \mathrm{C}$ for $10 \mathrm{~min}$ to remove cellular debris. The supernatant was collected and stored at $-80^{\circ} \mathrm{C}$ until assayed. CAT assay was performed following the manufacturer's instructions. Briefly, antibodies to CAT were precoated on the surface of the microtiter plate modules. Cell extracts were then added to the wells to allow CAT in the cell extracts to bind specifically to the precoated anti-CAT antibodies. A digoxigenin conjugated to peroxidase was added to bind to digoxigenin on anti-CAT antibodies. After incubation for $1 \mathrm{~h}$, CAT concentrations were determined by colorimetry (absorption at $405 \mathrm{~nm}$ against the reference wavelength of $492 \mathrm{~nm}$ ) using a VERSAmax tunable microtiter plate reader from Molecular Devices (Sunnyvale, CA).

Transient transfection and luciferase assay. HT22 cells were seeded into 12-well plates and grown $20-24 \mathrm{~h}$ to $70-80 \%$ confluence. Transient transfections were performed using Lipofectin reagent from Invitrogen Life Technologies (Carlsbad, CA) and pAH-Luc plasmid in serum-free medium. Stripped FBS was added to wells $5 \mathrm{~h}$ after transfection, according to the manufacturer's protocol. Drug treatments were carried out $24 \mathrm{~h}$ after transfection, and all samples were run in triplicate.

The treated HT22 cells were washed once with cold $1 \times$ PBS and lysed using a passive lysis buffer. Cells were then centrifuged at $10000 \mathrm{rpm}$ for $15 \mathrm{~s}$ at RT to remove cellular debris. Luciferase activity was measured using microplate luminometer (Labsystems, Helsinki, Finland) and luciferin substrate (Promega, Madison, WI), according to the instruction from the manufacturer.

Nuclear/cytosol extraction. Cells were cultured in 100-mm cell culture dishes until $100 \%$ confluent. Cells were treated with various concentrations of SP and Dex for $2 \mathrm{~h}$. Cells were harvested in $5 \mathrm{ml}$ ice-cold PBS. The cells were pelleted for $5 \mathrm{~min}$ at $1200 \mathrm{rpm}\left(4^{\circ} \mathrm{C}\right)$. The cell pellets were then resuspended in $200 \mu \mathrm{l}$ cold low-salt buffer (containing $20 \mathrm{mM}$ HEPES, pH 7.9, $10 \mathrm{mM} \mathrm{KCl}, 0.1 \mathrm{mM} \mathrm{Na} \mathrm{NO}_{3}$, $1 \mathrm{mM}$ EDTA, $1 \mathrm{mM}$ EGTA, $0.2 \%$ Nonidet P- $40,10 \%$ glycerol, $0.5 \mathrm{mM}$ PMSF, and $1 \mathrm{mM}$ DTT) and mixed by gentle pipetting and vortexing. After incubating on ice for $15 \mathrm{~min}$, cells were centrifuged for $10 \mathrm{~min}$ at $3000 \mathrm{rpm}$ $\left(4^{\circ} \mathrm{C}\right)$. For cytosolic GR binding assays, supernatants were transferred to ultracentrifuge tubes and spun for $30 \mathrm{~min}$ at $48000 \mathrm{rpm}\left(4^{\circ} \mathrm{C}\right)$ to extract cytosol. The pellets were resuspended in $5 \mathrm{ml}$ low-salt buffer without Nonidet P-40 and pelleted for $10 \mathrm{~min}$ at $3000 \mathrm{rpm}\left(4^{\circ} \mathrm{C}\right)$. The nuclei pellets were resuspended in $150 \mu \mathrm{l}$ high-salt buffer (20 mM HEPES, pH 7.9, $420 \mathrm{mM} \mathrm{NaCl}, 10 \mathrm{mM} \mathrm{KCl}, 0.1 \mathrm{mM} \mathrm{Na} \mathrm{VO}_{4}, 1 \mathrm{mM}$ EDTA, 1 mM EGTA, 20\% glycerol, $0.5 \mathrm{mM}$ PMSF, and $1 \mathrm{mM}$ DTT) and vigorously rocked for $30 \mathrm{~min}$ at $4^{\circ} \mathrm{C}$. Nuclear extracts were collected after centrifugation for $30 \mathrm{~min}$ at $48000 \mathrm{rpm}\left(4^{\circ} \mathrm{C}\right)$.

Protein concentration determination. Protein concentrations were determined using a commercial bicinchoninic acid (BCA) kit from Pierce (Rockford, IL) following the manufacturer's instructions. Protein samples were alkalized with the supplied reagent and incubated with the reaction reagent containing $\mathrm{Cu}^{2+}$ to produce a purple color for colorimetric detection against a BSA protein standard. Due to potential variations in cell harvesting, protein concentrations were used to normalize sample loading for relevant assays.

Gel mobility shift assay. Synthetic oligonucleotides containing GRE (5'-AAG ATT CAG GTC ATG ACC TGA GGA GA) and AP-1 (5'-CGC TTG ATG AGT CAG CCG GAA) 
sequences were obtained from Invitrogen. The oligonucleotides were annealed and then labeled at the $5^{\prime}$ end using T4polynucleotide kinase and $\left[\gamma-{ }^{32} \mathrm{P}\right] \mathrm{ATP}$, according to the manufacturer's instructions. In total, $5-10 \mu \mathrm{g}$ of nuclear extracts from various treatments were incubated with $1 \mu \mathrm{g}$ poly $d(I-C)$ for $15 \mathrm{~min}$ at RT to bind nonspecific DNAbinding proteins. A measure of $1 \mu \mathrm{l}\left[{ }^{32} \mathrm{P}\right] \mathrm{DNA}$ (final concentration, $1 \mathrm{nM}$ ) was added and incubated for $15 \mathrm{~min}$ at RT. In total, 100-fold excess DNA was added 5 min before additional $\left[{ }^{32} \mathrm{P}\right] \mathrm{DNA}$ to compete with the specific DNAprotein binding. Reaction mixtures were loaded onto a $5 \%$ nondenaturing polyacrylamide gel (acrylamide:bisacrylamide, $30: 0.8)$ and run at $150 \mathrm{~V}$ in $1 \times$ TBE buffer $(0.09 \mathrm{M}$ Tris, $0.09 \mathrm{M}$ borate, and $2 \mathrm{mM}$ EDTA, $\mathrm{pH} 8.3$ ) until the bromophenol blue reached the bottom. Gels were dried, and protein-DNA binding was visualized by autoradiography or analyzed using PhosphorImager.

JNK activity measurement. Cells were cultured in $60-\mathrm{mm}$ cell culture dishes until $100 \%$ confluent. Cells were then treated with varying doses of SP and/or $50 \mathrm{nM}$ Dex and harvested after $2 \mathrm{~h}$. Cells were washed once with cold $1 \times$ PBS, scraped into $0.5 \mathrm{ml} 1 \times$ SDS sample buffer and transferred to a centrifuge tube. The cells were then sonicated for $10-15 \mathrm{~s}$ and kept on ice. Cells were aliquoted and stored at $-80^{\circ} \mathrm{C}$ for later use. JNK activity was determined using Western blot as described below.

Western blotting analysis. Western blot analysis was performed on cytosol, nuclear extracts, and whole cell extracts. Cell lysates were prepared as described above. In total, $50 \mu \mathrm{g}$ cytosolic protein or $10 \mu \mathrm{g}$ whole-cell extracts were mixed with SDS sample buffer and subjected to SDS-PAGE (8 or $12 \%$ gel). For the nuclear Western assay, $25 \mu \mathrm{g}$ protein was mixed with SDS sample buffer and subjected to SDS-PAGE ( $8 \%$ gel). The separated proteins were then electrophoretically transferred onto a nitrocellulose membrane. The membrane was blocked for $1 \mathrm{~h}$ in a $5 \%$ milk/TBS solution, and then incubated in the presence of the 'primary antibody' ( $1: 1000$ dilution) for $3 \mathrm{~h}$. The washed membrane was then incubated with the secondary antibody $(1: 2000$ dilution) for $1 \mathrm{~h}$. The membrane was washed using a commercially available chemoluminescence kit from Amersham Biosciences Corp. (Piscataway, NJ) and exposed to autoradiographic film (Kodak).

Cytosolic GR binding. After incubation with drugs for $2 \mathrm{~h}$ in 100 -mm dishes, the HT22 cells were washed once with icecold PBS, scraped into $5 \mathrm{ml}$ cold PBS, and transferred to centrifuge tubes on ice. Cells were pelleted at $700 \mathrm{~g}$ for $10 \mathrm{~min}\left(4^{\circ} \mathrm{C}\right)$. Pellets were resuspended in $1 \mathrm{ml}$ cold PBS and transferred to new centrifuge tubes on ice. Cells were then pelleted for $15 \mathrm{~min}$ at $700 \mathrm{~g}\left(4^{\circ} \mathrm{C}\right)$ and stored at $-80^{\circ} \mathrm{C}$ after removal of PBS.

GR binding was determined using a previously described in vitro cytosoloic exchange assay (Pariante et al, 1999). Cells were lysed using a freeze/thaw procedure in $250 \mu$ of binding buffer (1 mM EDTA, $10 \mathrm{mM}$ Tris, $20 \mathrm{mM}$ molybdic acid, $10 \%$ glycerol, $1 \mathrm{mM}$ DTT in double-distilled water, $\mathrm{pH}$ 7.4 at $4^{\circ} \mathrm{C}$ ), yielding an approximate final protein concen- tration of $0.5-2.5 \mathrm{mg} / \mathrm{ml}$ of cytosol. After centrifugation at $48000 \mathrm{rpm}$ for $30 \mathrm{~min}$ at $4^{\circ} \mathrm{C}$, the supernatant was added to incubation solutions containing radiolabeled $\left[{ }^{3} \mathrm{H}\right]$ Dex with or without unlabeled Dex. The cytosol extract + Dex solution was incubated at $4{ }^{\circ} \mathrm{C}$ overnight in order for the ligand/receptor binding reaction to come to equilibrium. Bound radiolabeled Dex was separated from unbound Dex by filtration through minicolumns containing $1.25 \mathrm{ml}$ of LH-20 Sephadex (Pharmacia, Piscataway, NJ). The eluant containing the bound fraction of steroid was added to $4 \mathrm{ml}$ of scintillation fluor (Ultima Gold, Packard, Meridien, CT), and $3 \mathrm{H}$ radioactivity was determined in a liquid scintillation counter. The amount of specific binding was defined as the amount of total 3H-Dex binding displaced by cold Dex. Specific GR binding is expressed as fmol/mg cytosolic protein. Protein content was determined using the Bradford method.

Antisense oligonucleotide treatment. JNK1 antisense oligonucleotides and the complementary sense oligonucleotides were synthesized by Qiagen, Valencia, CA. The oligonucleotides were phosphorothioated at the $3^{\prime}$-end (3 last bases) to confer nuclease resistance. The sequence of the JNK1 antisense probe was 5'-AGTTCTCGGTA GGCTCGCT- $3^{\prime}$ and the sense $5^{\prime}$-AGCGAGCCTACCGAGA ACT- $3^{\prime}$, using antisense design tool on the website, biotools.idtdna.com. Cells were transfected with oligonucleotides using Lipofectin reagent in serum-free medium for $5 \mathrm{~h}$ and then maintained in culture for $48 \mathrm{~h}$ in complete medium before harvesting.

Data analysis and statistics. Descriptive statistics (including the mean and standard deviation) were used to characterize the dependent measures in all of the studies. A two-way analysis of variance (ANOVA) was used to assess for main effects and interactions of treatment condition and dose and/or time. For all ANOVAs, both the Student-Newman-Keuls method and the Student's $t$-test were used for post hoc tests of significant differences between specific means in order to include both a conservative (Student-Newman-Keuls) and a powerful (Student's $t$-test) assessment of statistical significance. The level of significance was set at $p<0.05$, and all tests of significance were two-tailed.

\section{RESULTS}

\section{SP-600125 Inhibits JNK Activity and AP-1 Binding}

SP-600125, a selective JNK inhibitor, has been reported to dose-dependently inhibit JNK activity and phosphorylation of c-Jun in cultured cells (Bennett et al, 2001). SP-600125 has also been shown to inhibit JNK-mediated expression of inflammatory genes including COX-2, IL-2, TNF- $\alpha$, and IFN- $\gamma$. Nevertheless, there are limited data regarding the effects of SP-600125 on hippocampal cells, despite the importance of JNK pathways in apoptosis and inflammation in the central nervous system. Mouse hippocampal HT22 cells were treated with SP-600125 $(1-10 \mu \mathrm{M})$ for $2 \mathrm{~h}$, and $10 \mu \mathrm{g}$ protein from each treatment was separated on a $12 \%$ SDS-PAGE and blotted using monoclonal antibodies against either p-c-Jun or actin as described above. As seen in 
Figure 1a, SP-600125 at $10 \mu \mathrm{M}$ significantly inhibited the phosphorylation of c-Jun by $36 \%(p<0.001)$, whereas SP600125 at $1 \mu \mathrm{M}$ and Dex at $50 \mathrm{nM}$ had no significant effects. Results from gel mobility shift experiment were also consistent as seen in Figure 1b, SP-600125 at $10 \mu \mathrm{M}$ significantly inhibited AP-1 binding, but SP-600125 at $1 \mu \mathrm{M}$ and Dex at $50 \mathrm{nM}$ had no observable effect.

\section{SP-600125 Induces GR-Mediated Function}

We are aware of no reports regarding the effects of SP600125 on GR function. We transiently transfected the MMTV-luciferase plasmid into HT22 cells and treated cells with various concentrations of SP-600125 from 0.1 to $10 \mu \mathrm{M}$ for $24 \mathrm{~h}$. As shown in Figure 2, SP-600125 alone at concentrations of 1 and $10 \mu \mathrm{M}$ caused a significant dosedependent induction of GR-mediated luciferase activity $(p<0.001)$. In order to further understand the effects of inhibition of JNK by SP-600125 on Dex-induced response, various concentrations of SP-600125 were co-treated with Dex $(50 \mathrm{nM})$ for $24 \mathrm{~h}$. The results showed that SP-600125 at

a

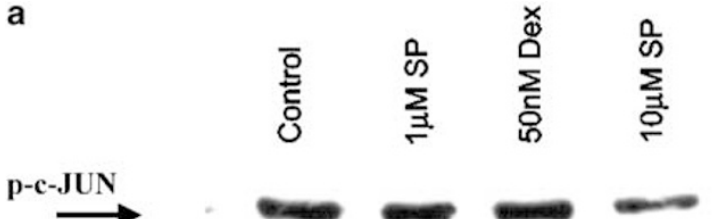

p-c-JUN
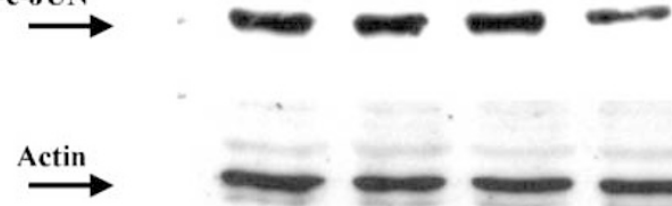

b
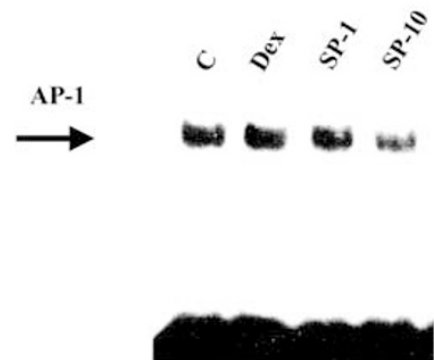

Figure I (a) Effect of SP-600I 25 on JNK MAPK activity. HT22 cells were grown in 60-mm culture dishes until 100\% confluent. Cells were then treated with SP-600I25 (I or $10 \mu \mathrm{M})$ or Dexamethasone (Dex) $(50 \mathrm{nM})$ for $2 \mathrm{~h}$. Cells were harvested using lysis buffer, and $50 \mu \mathrm{g}$ protein from each group was separated on a 12\% SDS-PAGE and transferred onto a nitrocellulose membrane. JNK MAP kinase assay kit from Cell Signaling using monoclonal antibody to p-c-Jun was employed as described in the Materials and methods. Actin was used as a loading control. Representative results from three separate experiments are shown. (b) Effect of SP600125 on AP-I binding. HT22 cells were grown in 100-mm culture dishes until 100\% confluency. Cells were then treated with SP-600I25 (I or $10 \mu \mathrm{M})$ or Dexamethasone $(50 \mathrm{nM})$ for $2 \mathrm{~h}$. Cells were harvested by using rubber policeman into $5 \mathrm{ml}$ ice-cold PBS and nuclear extraction was performed as described in the Materials and methods. In total, $10 \mu \mathrm{g}$ nuclear protein from each group was used in gel mobility shift assay using ${ }^{32} \mathrm{P}$-labeled synthetic AP-I oligos, and the results are shown. Only SP600125 at $10 \mu \mathrm{M}$ shows inhibition of AP-I binding. Data are from a representative experiment of three separate experiments.

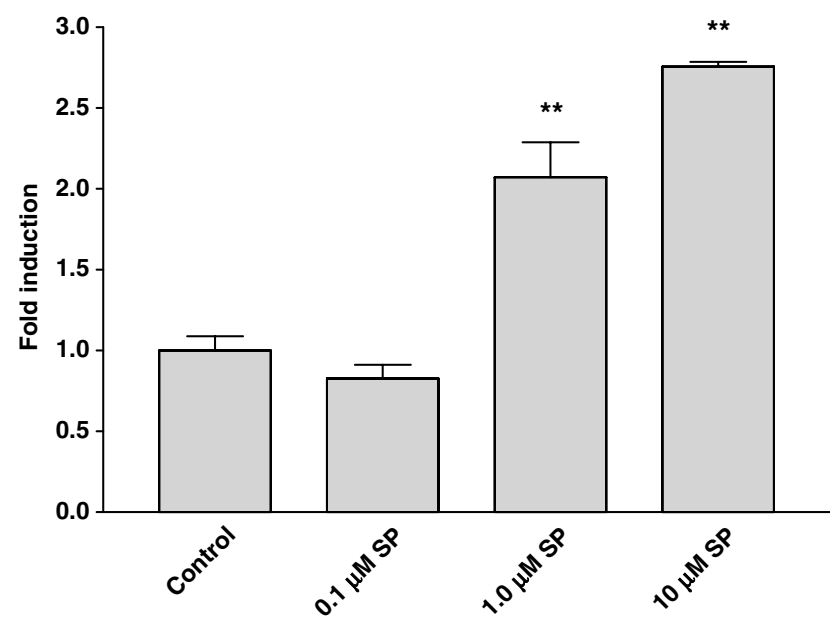

Figure 2 Effect of SP-600I25 on MMTV-luciferase activity. HT22 cells were grown in 12-well culture plates until $80 \%$ confluency. Transient transfections were performed using Lipofectin reagent and pAH-Luc plasmid in serum-free medium. Cells were treated with SP-600I25 at different concentrations as indicated for $24 \mathrm{~h}$ after transfection, and all samples were in triplicate. The luciferase activity was measured as described in the methods. Data were presented as mean \pm SE. $* * * 0.001$.

$10 \mu \mathrm{M}$ caused significant further enhancement of Dex-induced luciferase activity $(p<0.001)$ (Figure $3 a$ ). These results were also replicated in mouse fibroblast LMCAT cells (Figure 3b). In addition, SP-600125 (1 $\mu \mathrm{M})$ further enhanced corticosterone(Cort)-induced CAT activity $(p<0.001)$, indicating that the effects of SP-600125 on GR function were independent of the p-glycoprotein multidrug resistance pump (for which corticosterone is not a substrate). Gel shift assay was used to study the effects of SP-600125 on GR-DNA binding. As shown in Figure 4, 2-h treatment of HTT 22 cells with SP-600125 at $10 \mu \mathrm{M}$ led to comparable GR-GRE binding as was seen with Dex treatment. The combination of SP-600125 and Dex caused stronger GR-GRE binding, consistent with the impact of SP-600125 on GR-mediated luciferase and CAT activity.

Although SP-600125 is reported to be a very selective JNK inhibitor, it does have some inhibitory activities on other kinases including MKK3, MKK4, MKK7, Akt, and PKC $\alpha$ (Bennett et al, 2001). Antisense techniques have been widely used to selectively target relevant signaling pathways. Accordingly, we used a synthetic specific JNK antisense oligonucleotide matched with a JNK sense oligonucleotide as a control. As seen in Figure 5a, JNK antisense treatment significantly reduced JNK protein levels. Moreover, as shown in Figure 5b, treatment with the antisense oligonucleotide at a concentration of $0.5 \mu \mathrm{M}$ was associated with significant induction of luciferase activity ( $v s$ the sense oligonucleotide) both in the presence and absence of Dex $(p<0.05$ and $<0.001$, respectively).

\section{SP-600125 has no Effects on Cytosolic GR Binding Affinity and Nuclear Translocation}

The molecular mechanism of SP-600125's effects on GR function was further explored by examining cytosolic GR binding studied using $\left[{ }^{3} \mathrm{H}\right]$ Dex. As shown in Figure 6, SP- 

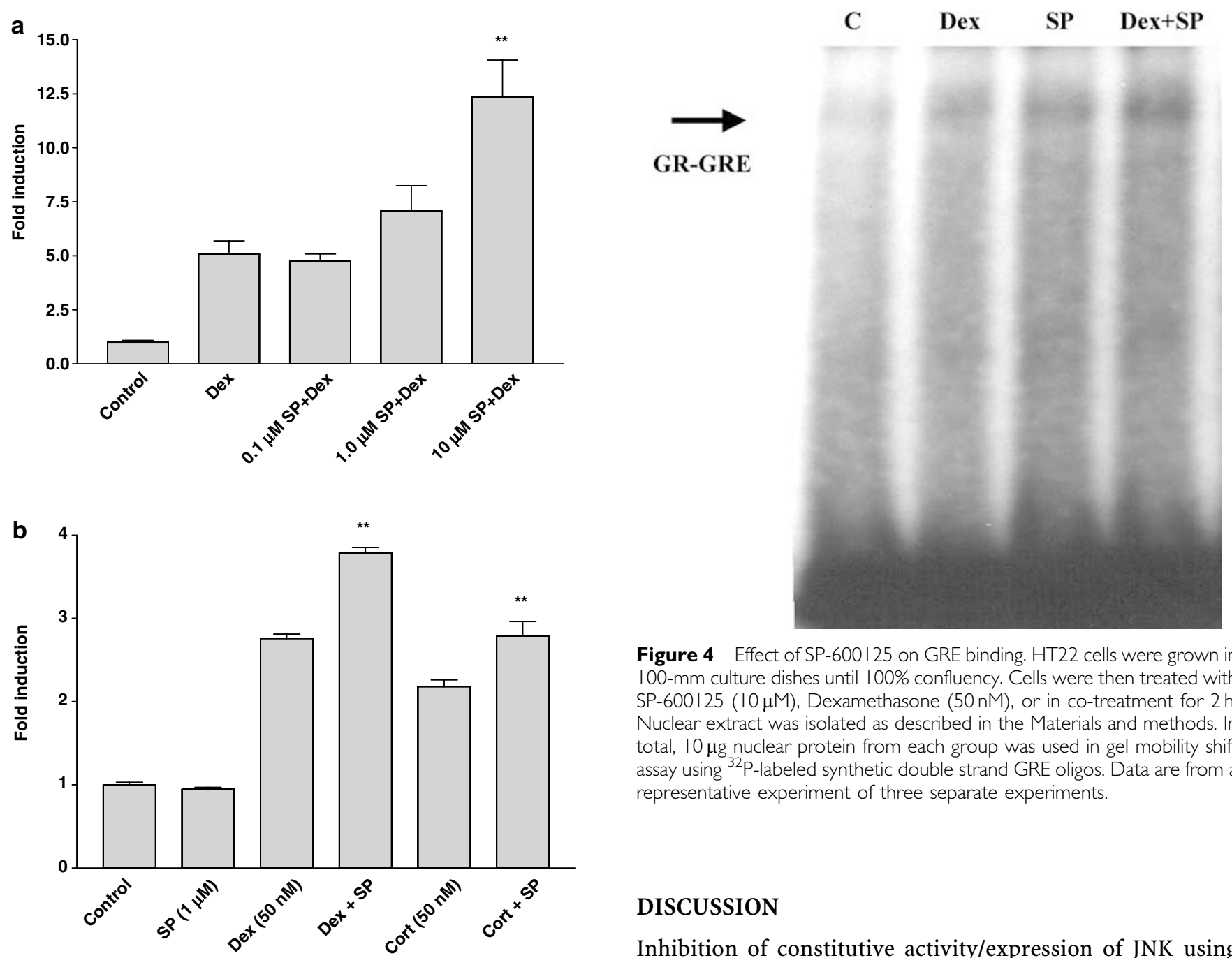

Figure 4 Effect of SP-600 I 25 on GRE binding. HT22 cells were grown in 100-mm culture dishes until 100\% confluency. Cells were then treated with SP-600 I $25(10 \mu \mathrm{M})$, Dexamethasone $(50 \mathrm{nM})$, or in co-treatment for $2 \mathrm{~h}$. Nuclear extract was isolated as described in the Materials and methods. In total, $10 \mu \mathrm{g}$ nuclear protein from each group was used in gel mobility shift assay using ${ }^{32}$ P-labeled synthetic double strand GRE oligos. Data are from a representative experiment of three separate experiments.

Figure 3 Effect of SP-600I 25 on Dex-induced MMTV-luciferase activity and Dex/Cort-induced CAT activity. (a) HT22 cells were grown in I2-well culture plates until $80 \%$ confluency. Transient transfections were performed as described. Cells were treated with SP-600I25 at different concentrations as indicated for $24 \mathrm{~h}$ after transfection with or without co-treatment with Dex $(50 \mathrm{nM})$, and all samples were in triplicate. The luciferase activity was measured as described in the Materials and methods. Data were presented as mean \pm SE. $* * * 00.00$ I. (b) LMCAT cells were grown in sixwell plates until $80 \%$ confluency. Cells were treated with SP-600I25 at different concentrations as indicated for $24 \mathrm{~h}$ with or without co-treatment with Dex $(50 \mathrm{nM})$ or Cort $(50 \mathrm{nM})$, and all samples were run in triplicate. The CAT activity was measured as described in the Materials and methods. Data were presented as mean \pm SE. $* * * 00.001$.

600125 at 1 and $10 \mu \mathrm{M}$ had no effects on cytosolic GR binding $(p>0.05)$, whereas Dex caused a significant reduction $(p<0.001)$ in cytosolic GR binding as expected. The effects of SP-600125 on GR nuclear translocation were also studied. HT22 cells were treated with Dex (50 nM) or SP-600125 (1 or $10 \mu \mathrm{M})$ for $2 \mathrm{~h}$, and Western blot was performed using a polyclonal GR antibody to probe both cytosol and nuclear extracts. As seen in Figure 7, only Dex induced a significant GR nuclear translocation $(p<0.001)$, whereas SP-600125 at 1 or $10 \mu \mathrm{M}$ had no observable effect.

\section{DISCUSSION}

Inhibition of constitutive activity/expression of JNK using the selective JNK inhibitor, SP-600125, or a JNK antisense oligonucleotide resulted in significant enhancement of GR function. This effect was not due to a measurable change in cytosolic GR binding nor GR nuclear translocation. Furthermore, the induction of GR-GRE binding by SP600125 occurred within 2-h suggesting that alterations in GR gene transcription or translation were not involved.

JNK is an important member of the MAPK family and plays a broad role in cellular responses to environmental stimuli, including inflammatory cytokines, bacterial endotoxin (lipopolysaccharide), osmotic shock, UV radiation, and hypoxia (Barr and Bogoyevitch, 2001). Of relevance to GR function, several studies have reported that activation of JNK pathways leads to inhibition of GR function. Molecular mechanisms that contribute to these inhibitory effects include increased GR nuclear export (Itoh et al, 2002), increased GR phosphorylation at Ser226 (Itoh et al, 2002) and Ser246 (Rogatsky et al, 1998), and increased Jun-GR binding (Yang-Yen et al, 1990; Schule et al, 1990).

In terms of the mechanism of the effects observed in this study, the data reported herein support the role of nuclear Jun-GR interactions in JNK-mediated inhibition of GR function under resting (nonstimulated) conditions. Increased GR activity following JNK inhibition was observed within $2 \mathrm{~h}$, corresponding with the inhibition of $\mathrm{c}$-Jun phosphorylation and AP1 binding. The lack of the effect of 

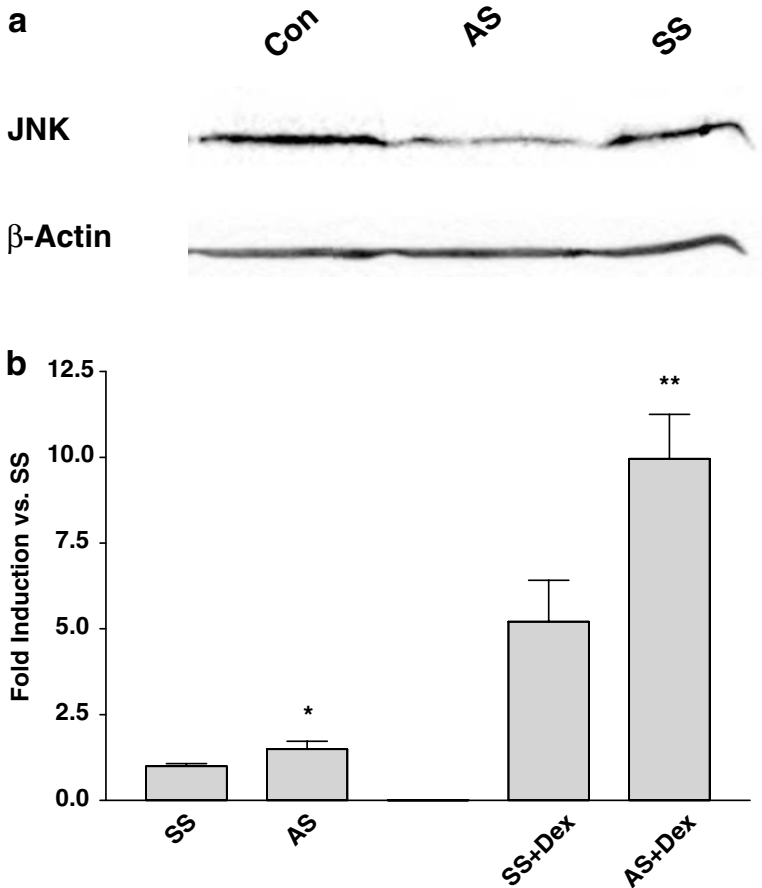

Figure 5 Effect of JNK antisense oligonucleotide on MMTV-luciferase activity and JNK protein. (a) HT22 cells were grown in six-well culture plates until $80 \%$ confluency. Transient transfections were performed using Lipofectin reagent with I $\mu \mathrm{M}$ JNK sense or antisense oligonucleotide in serum-free medium. Total cell extract were isolated after 48-h transfection. In total, $50 \mu \mathrm{g}$ protein from each group were analyzed by Western blot using polyclonal JNK and $\beta$-actin antibody. Results shown are from a representative experiment of three separate experiments. (b) HT22 cells were grown in 12-well culture plates until $80 \%$ confluency. Transient transfections were performed using Lipofectin reagent and pAH-Luc plasmid with $0.5 \mu \mathrm{M}$ JNK sense or antisense oligonucleotide in serum-free medium. Cells were treated with or without Dex $(50 \mathrm{nM})$ for $24 \mathrm{~h}$ after transfection, and all samples were in triplicate. The luciferase activity was measured as described in the Materials and methods. Data were presented as mean \pm SE. $* p<0.05$, *** $p<0.001$.

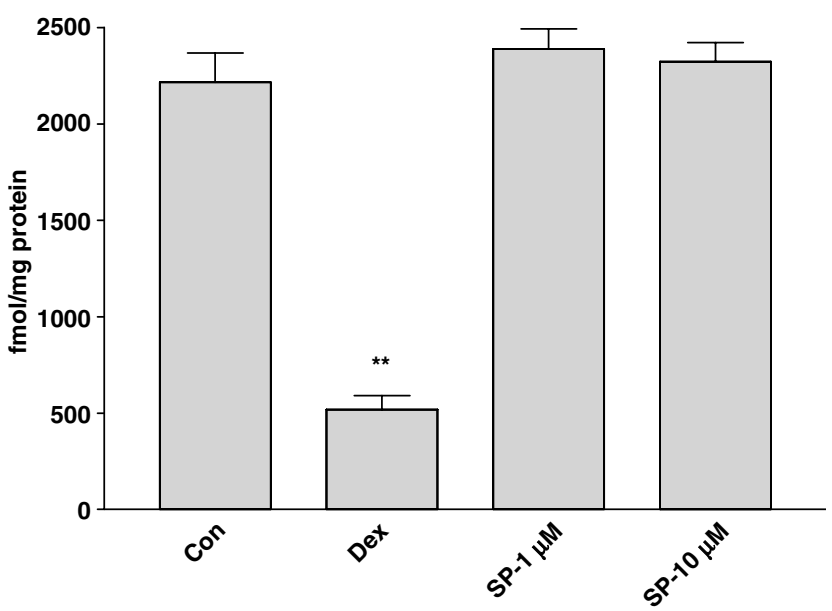

Figure 6 Effect of SP-600I25 on GR cytosolic binding. HT22 cells were grown in 100-mm culture dishes until 100\% confluent. Cells were harvested after treated with SP-600I25 (I and 10 $\mu$ M), Dex (50 nM) for $2 \mathrm{~h}$. Cytosolic GR binding was carried out as described in the Materials and methods. Specific GR binding is expressed as fmol/mg cytosolic protein. Data were presented as mean $\pm \mathrm{SE}$. $* * * 0.001$.

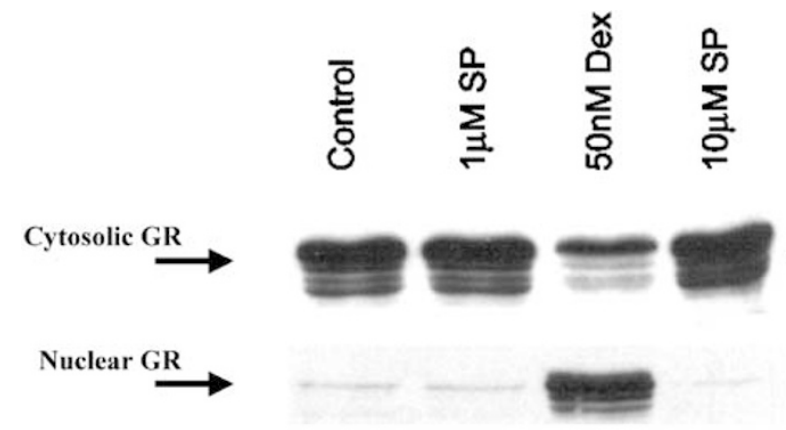

Figure 7 Effect of SP-600I25 on GR nuclear translocation. HT22 cells were grown in 100-mm culture dishes until 100\% confluency. Cells were then treated with SP-600 I 25 (I or $25 \mu \mathrm{M}$ ) or Dexamethasone $(50 \mathrm{nM}$ ) for $2 \mathrm{~h}$. Both cytosolic and nuclear extract were isolated as described in the Materials and methods. In total, $25 \mu \mathrm{g}$ nuclear protein or $50 \mu \mathrm{g}$ cytosolic protein from each group were analyzed by Western blot using polyclonal GR antibody. Results shown are from a representative experiment of three separate experiments.

JNK inhibition on GR nuclear translocation argues against the contribution of GR nuclear export in these results, and suggests that increased nuclear translocation is not a necessary prerequisite to increase GR-GRE binding. Indeed, although nuclear GR levels were unaffected by SP-600125, 'functional' nuclear GR (as assessed by gel mobility shift assay) were increased, possibly due to reduced JNK-related effects on the phosphorylation state of the GR and/or associated steroid receptor cofactors. Of note, JNK inhibition had no effect on GR protein expression, further supporting the notion that GR gene transcription and translation were not involved in the effects of JNK on GR. Taken together, the data suggest that JNK regulation of the GR under resting conditions appears to involve interactions that occur in the nucleus between GR and c-Jun (or other steroid receptor regulatory factors), which serve to tonically inhibit GR function.

Previous data indicate that inhibitors of MAPK pathways (including the p38 MAPK inhibitor, SB203580) may alter GR activity through effects on the p-glycoprotein multiple drug resistance (mdr) pump, which regulates intracellular concentrations of certain pharmacologic agents (including Dex) (Wang et al, 2004; Barancik et al, 2001). Nevertheless, our data show that JNK inhibition led to increased GR function using both Dex (a substrate of the mdr pump) and Cort (not a substrate of the mdr pump), suggesting that the GR enhancing effect of JNK inhibition was not due to $\mathrm{mdr}$ pump inhibition.

It should be noted that $1 \mu \mathrm{M}$ SP-600125 significantly increased GR-mediated gene transcription in the absence of hormone, yet, at this concentration, there was no effect on JNK. This discrepancy likely reflects the greater sensitivity of the luciferase assay system as compared to the detection threshold for changes in JNK activity (as measured by phosphorylation of c-JUN). A similar phenomenon may hold true for the relationship between the luciferase assay system and the gel mobility shift assay, where equivalent levels of GR-GRE binding (between Dex and SP-600125) were associated with different transcriptional activities, although it is conceivable that DNA binding of a steroidbound receptor might be more transcriptionally active than 
nuclear GR (and/or nuclear GR co-factors) released from constitutive-inhibition by JNK.

These data regarding the GR effects of JNK, together with our recent findings that $\mathrm{p} 38$ MAPK pathways are involved in IL-1 alpha-induced inhibition of GR function (Wang et al, 2004), demonstrate that MAPK pathways are involved in the negative regulation of GR and may thereby contribute to the development of the glucocorticoid resistance that has been reported in certain chronic inflammatory and infectious diseases as well as major depression. Indeed, major depression has been associated with increased concentrations of proinflammatory cytokines including IL-1, which is capable of activation of both JNK and MAPK (Saklatvala et al, 1999; Raison and Miller, 2001; Wang et al, 2004). Thus, restoration of glucocorticoid-mediated negative feedback in these conditions may be achieved in part by inhibition of JNK or p38 MAPK pathways. In addition, in view of recent data that JNK pathways may contribute to cell death in multiple tissues (Yue et al, 1998), inhibition of JNK activity may address numerous relevant pathophysiologic targets in diseases characterized by glucocorticoid resistance, inflammation, and cell death.

Although the role of JNK pathways has been extensively studied in the regulation of immune and inflammatory responses, the effects of JNK inhibition on GR function in HT22 cells support the relevance of these pathways to cells of nervous system origin. Indeed, the mouse hippocampal HT22 cell line has been widely used as an in vitro model system to study signal transduction pathways involving Jun (Rossler et al, 2002), g-proteins (Ignatov et al, 2003), and glucocorticoids (Schmidt et al, 2001) as well as oxidative stress (Behl, 2000), the effects of antidepressants (Herr et al, 2003), and the pathogenesis of Alzheimer disease (Behl, 1998). Moreover, inhibition of c-Jun activity has been found to increase sprouting and cell number in primary rat hippocampal neurons and reduce toxin-mediated cell death in nigrostriatal neurons (Schlingensiepen et al, 1993; Yue et al, 1998). Finally, given the role of hippocampal GR in feedback regulation of neuroendocrine responses, JNKrelated influences on the GR may play a role in the pathophysiology of altered hypothalamic-pituitary-adrenal axis function found in neuropsychiatric disorders including depression. For example, dexamethasone nonsuppression is a reliable finding in patients with major depression (Pariante and Miller, 2001) and has been correlated with increased plasma concentrations of IL-1 (an activator of JNK pathways) (Maes et al, 1993). Moreover, chronic treatment with the JNK activator, lipopolysaccharide, has been shown to lead to dexamethasone nonsuppression in rodents (Weidenfeld and Yirmiya, 1996; Yirmiya, 1996). Therefore, taken with its potential neuroprotective effects, inhibition of JNK pathways may provide a broad spectrum of relevant activities in the hippocampus and other tissues that may be important in addressing the pathophysiology of depression.

\section{ACKNOWLEDGEMENTS}

This work was supported in part by grant from the National Institute of Mental Health (MH-067041) and Emory University Research Committee Award.

\section{REFERENCES}

Barancik M, Bohacova V, Kvackajova J, Hudecova S, Krizanova O, Breier A (2001). SB203580, a specific inhibitor of p38-MAPK pathway, is a new reversal agent of P-glycoprotein-mediated multidrug resistance. Eur J Pharm Sci 14: 29-36.

Barr RK, Bogoyevitch MA (2001). The c-Jun N-terminal protein kinase family of mitogen-activated protein kinases (JNK MAPKs). Int J Biochem Cell Biol 33: 1047-1063.

Behl C (1998). Effects of glucocorticoids on oxidative stressinduced hippocampal cell death: implications for the pathogenesis of Alzheimer's disease. Exp Gerontol 33: 689-696.

Behl C (2000). Vitamin E protects neurons against oxidative cell death in vitro more effectively than 17-beta estradiol and induces the activity of the transcription factor NF-kappaB. J Neural Transm 107: 393-407.

Bennett BL, Sasaki DT, Murray BW, O'Leary EC, Sakata ST, $\mathrm{Xu}$ W et al (2001). SP600125, an anthrapyrazolone inhibitor of Jun N-terminal kinase. Proc Natl Acad Sci USA 98: 13681-13686.

Corrigan CJ, Brown PH, Barnes NC, Szefler SJ, Tsai JJ, Frew AJ et al (1991). Glucocorticoid resistance in chronic asthma. Glucocorticoid pharmacokinetics, glucocorticoid receptor characteristics, and inhibition of peripheral blood $\mathrm{T}$ cell proliferation by glucocorticoids in vitro. Am Rev Respir Dis 144: 1016-1025.

Herr AS, Tsolakidou AF, Yassouridis A, Holsboer F, Rein T (2003). Antidepressants differentially influence the transcriptional activity of the glucocorticoid receptor in vitro. Neuroendocrinology 78: 12-22.

Holsboer F (2000). The corticosteroid receptor hypothesis of depression. Neuropsychopharmacology 23: 477-501.

Ignatov A, Lintzel J, Hermans-Borgmeyer I, Kreienkamp HJ, Joost P, Thomsen S et al (2003). Role of the G-protein-coupled receptor GPR12 as high-affinity receptor for sphingosylphosphorylcholine and its expression and function in brain development. J Neurosci 23: 907-914.

Itoh M, Adachi M, Yasui H, Takekawa M, Tanaka H, Imai K (2002). Nuclear export of glucocorticoid receptor is enhanced by c-Jun $\mathrm{N}$-terminal kinase-mediated phosphorylation. Mol Endocrinol 16: 2382-2392.

Jonat C, Rahmsdorf HJ, Park KK, Cato AC, Gebel S, Ponta H et al (1990). Antitumor promotion and antiinflammation: downmodulation of AP-1 (Fos/Jun) activity by glucocorticoid hormone. Cell 62: 1189-1204.

Lamberts SW (1996). The glucocorticoid insensitivity syndrome. Horm Res 45: 2-4.

Maes M, Bosmans E, Meltzer HY, Scharpe S, Suy E (1993). Interleukin-1 beta: a putative mediator of HPA axis hyperactivity in major depression? Am J Psychiatry 150: 1189-1193.

Manning AM, Davis RJ, Weston CR (2003). Targeting JNK for therapeutic benefit: from junk to gold? The JNK signal transduction pathway. Nat Rev Drug Discov 2: 554-565.

Miller AH, Pariante CM, Pearce BD (1999). Effects of cytokines on glucocorticoid receptor expression and function. Glucocorticoid resistance and relevance to depression. Adv Exp Med Biol 461: 107-116.

Norbiato G, Bevilacqua M, Vago T, Clerici M (1996). Glucocorticoids and interferon-alpha in the acquired immunodeficiency syndrome. J Clin Endocrinol Metab 81: 2601-2606.

Pariante CM, Miller AH (2001). Glucocorticoid receptors in major depression: relevance to pathophysiology and treatment. Biol Psychiatry 49: 391-404.

Pariante CM, Pearce BD, Pisell TL, Sanchez CI, Po C, Su C et al (1999). The proinflammatory cytokine, interleukin-1alpha, reduces glucocorticoid receptor translocation and function. Endocrinology 140: 4359-4366.

Raison CL, Miller AH (2001). The neuroimmunology of stress and depression. Semin Clin Neuropsychiatry 6: 277-294. 
Reichardt HM, Kaestner KH, Tuckermann J, Kretz O, Wessely O, Bock R et al (1998). DNA binding of the glucocorticoid receptor is not essential for survival. Cell 93: 531-541.

Rogatsky I, Logan SK, Garabedian MJ (1998). Antagonism of glucocorticoid receptor transcriptional activation by the c-Jun N-terminal kinase. Proc Natl Acad Sci USA 95: 2050-2055.

Rossler OG, Steinmuller L, Giehl KM, Thiel G (2002). Role of c-Jun concentration in neuronal cell death. J Neurosci Res 70: 655-664.

Saklatvala J, Dean J, Finch A (1999). Protein kinase cascades in intracellular signalling by interleukin-I and tumour necrosis factor. Biochem Soc Symp 64: 63-77.

Schlingensiepen $\mathrm{KH}$, Schlingensiepen $\mathrm{R}$, Kunst M, Klinger I, Gerdes W, Seifert W et al (1993). Opposite functions of jun-B and c-jun in growth regulation and neuronal differentiation. Dev Genet 14: 305-312.

Schmidt P, Holsboer F, Spengler D (2001). Beta(2)-adrenergic receptors potentiate glucocorticoid receptor transactivation via $G$ protein beta gamma-subunits and the phosphoinositide 3-kinase pathway. Mol Endocrinol 15: 553-564.

Schule R, Rangarajan P, Kliewer S, Ransone LJ, Bolado J, Yang N et al (1990). Functional antagonism between oncoprotein c-Jun and the glucocorticoid receptor. Cell 62: 1217-1226.

Sher ER, Leung DY, Surs W, Kam JC, Zieg G, Kamada AK et al (1994). Steroid-resistant asthma. Cellular mechanisms contributing to inadequate response to glucocorticoid therapy. J Clin Invest 93: 33-39.

Shimada T, Hiwatashi N, Yamazaki H, Kinouchi Y, Toyota T (1997). Relationship between glucocorticoid receptor and response to glucocorticoid therapy in ulcerative colitis. Dis Colon Rectum 40: S54-S58.

Spahn J, Szefler S, Surs W, Doherty D, Nimmagadda S, Leung D (1996). A novel action of IL-13: induction of diminished monocyte glucocorticoid receptor-binding affinity. I Immunol 157: 2654-2659.

Wang X, Wu H, Miller AH (2004). Interleukin-1 alpha-induced activation of p38 mitogen-activated protein kinase inhibits glucocorticoid receptor function. Mol Psychiatry 9: 65-75.

Weidenfeld J, Yirmiya R (1996). Effects of bacterial endotoxin on the glucocorticoid feedback regulation of adrenocortical response to stress. Neuroimmunomodulation 3: 352-357.

Weston CR, Davis RJ (2002). The JNK signal transduction pathway. Curr Opin Genet Dev 12: 14-21.

Yang-Yen HF, Chambard JC, Sun YL, Smeal T, Schmidt TJ, Drouin $J$ et al (1990). Transcriptional interference between c-Jun and the glucocorticoid receptor: mutual inhibition of DNA binding due to direct protein-protein interaction. Cell 62: 1205-1215.

Yirmiya R (1996). Endotoxin produces a depressive-like episode in rats. Brain Res 711: 163-174.

Yue TL, Ma XL, Wang X, Romanic AM, Liu GL, Louden C et al (1998). Possible involvement of stress-activated protein kinase signaling pathway and Fas receptor expression in prevention of ischemia/reperfusion-induced cardiomyocyte apoptosis by carvedilol CEP-1347/KT-7515, an inhibitor of c-jun N-terminal kinase activation, attenuates the 1-methyl-4-phenyl tetrahydropyridine-mediated loss of nigrostriatal dopaminergic neurons in vivo. Circ Res 82: 166-174. 